\title{
XXXIX.
}

\section{Ueber die Aethylverbindungen der Bromüre von Wismuth, Antimon und Arsen.}

\author{
Von \\ J. Nicklès.
}

(Compt. rend. t. LII, p. 396.)

Antimon- und Arsenbromür lösen sich in wasserfreiem Aether und geben damit zwei Flüssigkeitsschichten, von denen die untere, mehr klebrige eine Verbindung des Bromürs mit Aether ist. Das Wismuthbromür giebt unter diesen Umständen keine Verbindung, sondern nur bei Anwendung von Druck oder durch indirecte Wirkung.

Diese beiden Verbindungen sind unlöslich oder wenig löslich in Aether oder Schwefelkohlenstoff, löslich in Alkohol und zersetzen sich mit Wasser unter Bildung von Alkohol und Oxybromür; sie werden auch durch Wärme zersetzt, selbst bei gewöhnlicher Temperatur, wenn man sie unter einer Glocke über Schwefelsäure aufbewahrt; der Rückstand ist mehr oder weniger reines Bromür. Sie zersetzen kohlensaure Alkalien unter Aufbrausen, werden durch trockenes Schwefelwasserstoffgas gefällt und absorbiren Ammoniak unter Entstehung eines ammoniakalischen Bromürs, das frei von organischer Substanz ist.

Bramwismuthdither. Wird Wismuthbromür, $\mathrm{BiBr}_{3}$, mit wasserfreiem Aether in einem verschlossenen Gefäss auf $100^{\circ}$ erhitzt, so löst es sich und bildet zwei Schichten, wovon die untere, gefärbte die ätherische Lösung der neuen Verbindung ist; man erhält sie auch durch Schütteln des Aethers mit Brom und gepulvertem Wismuth.

Die zwei Schichten bilden sich nicht, wenn der Aether Alkohol enthält, und verschwinden sogar, wenn man Alkohol zusetzt.

Im Vacuo und über Schwefelsäure krystallisirt der Bromwismuthäther in rhombischen, sehr deliquescenten 
Prismen, die schon nach wenigen Minuten an der Luft zerfliessen. Die Analyse gab 4 Aeq. Wasser.

Seine Zusammensetzung wird durch die Formel ausgedrückt:

$$
\begin{aligned}
& \mathrm{BiBr}_{3}+2 \mathrm{C}_{4} \mathrm{H}_{5} \mathrm{O}+4 \mathrm{HO} \text {. } \\
& \begin{array}{lccc} 
& \multicolumn{2}{c}{\text { Berechnet. }} & \text { Gefunden. } \\
\mathrm{BiBr}_{3} & 450 & - & - \\
\mathrm{C}_{8} & 48 & 8,57 & 8,47 \\
\mathrm{H}_{14} & 14 & \mathbf{2 , 5 0} & 2,54 \\
\mathrm{O}_{6} & 18 & - & -
\end{array}
\end{aligned}
$$

In der Wärme zerstört dieser Aether das Papier, besonders wenn er, wie gewöhnlich, Bromwasserstoffsäure enthält.

Wismuthchlorür verbindet sich gleichfalls mit Aether, Wismuthjodür ist ohne Wirkung.

Der Bromantimonather zersetzt sich durch Wärme nur theilweise, ohne $\mathrm{Zweifel}$ weil $\mathrm{SbBr}_{3}$ füchtiger ist als $\mathrm{BiBr}_{3}$; ein Theil geht bei der Destillation immer mit über neben freiem Aether, Bromwasserstoffsäure und Bromwasserstoffäther; der Rückstand ist $\mathrm{HBr}_{3}$, gefärbt durch Kohle.

Wird dieser Aether mit Brom und gepulvertem Antimon dargestellt, so ist er braun gefärbt durch ein wenig Bromkohlenwasserstoff, der sich auf Kosten des Broms und der Elemente des Aethers bildet.

Ich habe zwei Verbindungen des Bromürs mit Aether beobachtet, die eine mit 2 , die andere mit 4 Aeq. Aether. Die von mir untersuchten Verbindungen waren nicht destillirt; nachdem der Aether mit Brom und gepulvertem Antimon bis zur Sättigung behandelt worden war, filtrirte man die Flüssigkeit unter einer Glocke. Eine Verbrennung mit den ersten Portionen gab Zahlen, welche sich mit der Formel zu vereinigen scheinen:

$$
\mathrm{SbBr}_{3}+4 \mathrm{C}_{4} \mathrm{H}_{5} \mathrm{O}
$$

trotz des Ueberschusses an Kohlenstoff, vom Bromkohlenwasserstoff herrührend.

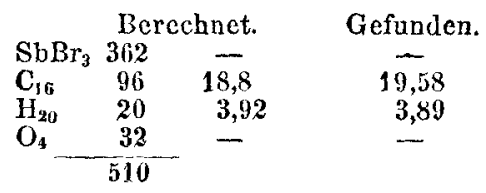


Die Verbindung mit 2 Aeq. Aether zeigte sich als eine weisse, sehr klebrige Flüssigkeit auf dem Filter.

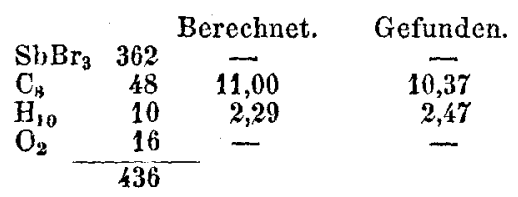

Die erste dieser beiden Verbindungen brennt mit weisser Flamme und lässt einen öligen, beim Erkalten krystallisirenden Rückstand; die zweite mit 2 Aeq. Aether brennt nur beim Erhitzen.

Die Eigenschaften des Bromarsenäthers sind denen der Antimonverbindung analog. $\mathrm{Er}$ ist flüchtiger als die beiden beschriebenen Verbindungen, aber eben so wenig beständig wie diese; denn unter einer Glocke und über Schwefelsäure verliert er in kurzer Zeit die Elemente des Aethers und hinterlässt glänzende lange, aneinander haftende Nadeln von Arsenbromür. Zink ist ohne Wirkung auf den Aether; er verflüchtigt sich theilweise in der Wärme.

Aehnliche Verbindungen können mit anderen Alkoholen und anderen Aethern erzeugt werden.

Das Antimonchlorür verhält sich unter diesen Umständen wie das Bromür und wie das Chlorarsen; dagegen bleiben Antimonjodür und Arsenjodür unangegriffen im pulverigen Zustande am Boden der Röhre.

Andere Metallbromüre verhalten sich wie die oben erwähnten, so z. B. die von Aluminium, Zink, Zinn, Quecksilber. Ueber dieselben werde ich später Mittheilungen geben. 